\title{
Endoscopic ultrasound in interventional pulmonology
}

\author{
Elliot Ho, Pravachan Hegde \\ Division of Interventional Pulmonology, University of California San Francisco, Fresno, CA, USA \\ Contributions: (I) Conception and design: All authors; (II) Administrative support: None; (III) Provision of study materials or patients: All authors; \\ (IV) Collection and assembly of data: All authors; (V) Data analysis and interpretation: All authors; (VI) Manuscript writing: All authors; (VII) Final \\ approval of manuscript: All authors. \\ Correspondence to: Pravachan Hegde. Division of Interventional Pulmonology, University of California San Francisco, Fresno, CA, USA. \\ Email: PHegde@fresno.ucsf.edu.
}

\begin{abstract}
Lung cancer is the leading cause of cancer related deaths worldwide. Accurate staging of the mediastinum is essential to determine the appropriate treatment plan in patients with potentially operable non-small cell lung cancers (NSCLC). Traditionally, the gold standard test in mediastinal staging has been cervical mediastinoscopy. However, this procedure is invasive, requires general anesthesia, and is associated with significant risk. Training in endoscopic ultrasound (EUS) techniques in addition to endobronchial ultrasound (EBUS) allows for diagnosis and complete staging of lung cancer in a single session, thereby decreasing healthcare cost, time delays, increased sedation time, and patient discomfort. With its superior cost-effectiveness and reduced risk profile compared to conventional mediastinoscopy, endoscopic approach has replaced mediastinoscopy as the initial step in lung cancer staging and diagnosis. Here we discuss the utility of EUS along with combined EBUS with EUS, and highlight some of the technical aspects of the procedure. We will review the current role of EUS technique for the evaluation of mediastinal adenopathy and staging of lung cancer. We will also briefly discuss its use in diagnosing mediastinal infection and granulomatous lesions in the thoracic cavity.
\end{abstract}

Keywords: Lung cancer; endoscopic ultrasound (EUS); complete staging

Received: 11 August 2019; Accepted: 19 November 2019; Published: 10 April 2020.

doi: $10.21037 /$ shc.2019.11.08

View this article at: http://dx.doi.org/10.21037/shc.2019.11.08

\section{Introduction}

Lung cancer is the leading cause of cancer related deaths worldwide (1). Routine lung cancer surveillance has resulted in early detection of pulmonary nodules and masses. Accurate staging of the mediastinum is essential to determine the appropriate treatment plan in patients with potentially operable non-small cell lung cancers (NSCLC). Early identification of positive N2 or N3 lymph nodes and distant metastases on positron emission tomographycomputed tomography (PET-CT) in combination with definitive tissue diagnosis prevents futile thoracotomies. Early detection of N1 lymph node metastases in candidates with poor lung function can also guide the decision process between stereotactic radiosurgery (SBRT) versus concurrent chemo-radiation (2).
Non-invasive radiological tests including computed tomography (CT) and PET-CT scans have improved radiological staging of lung cancer. However, these techniques cannot provide definitive tissue diagnosis and are associated with high false-positive rates and low sensitivities and specificities (3-11). Traditionally, the gold standard test in mediastinal staging has been cervical mediastinoscopy. However, this procedure is invasive, requires general anesthesia, and is associated with significant risk.

Needle sampling techniques with minimally invasive techniques such as endobronchial ultrasound (EBUS) and endoscopic ultrasound (EUS), or a combination of both, are proving to be extremely useful in the diagnosis and mediastinal staging of lung cancers (12-17). Currently, it is recommended as the initial approach and may be superior over surgical staging as the first test in lung cancer staging 
and diagnosis of mediastinal masses, lymphadenopathy, and metastatic disease (2,18-21).

Here we discuss the utility of EUS along with combined EBUS/EUS, and highlight some of the technical aspects of the procedure. We will review the current role of EUS technique for the evaluation of mediastinal adenopathy and staging of lung cancer. We will also briefly discuss its use in diagnosing mediastinal infection and granulomatous lesions in the thoracic cavity.

\section{Lung cancer staging and guidelines}

Lung cancer staging dictates therapy and prognosis. By identifying N2/N3 lymph nodes and distant metastases, it prevents futile surgery and identifies patients who may benefit from neoadjuvant treatment. Staging is also important in order to identify $\mathrm{N} 1$ lymph node metastases in candidates with poor lung function before planning SBRT or sub-lobar resection.

Current European Society of Gastrointestinal Endoscopy (ESGE), European Respiratory Society (ERS), European Society of Thoracic Surgeons (ESTS), American College of Chest Physicians (ACCP), and National Comprehensive Cancer Network (NCCN) guidelines recommend staging in all central tumors, peripheral tumors $>3 \mathrm{~cm}$, lymph nodes $>1 \mathrm{~cm}$ on CT scan, N1 lymph node involvement on PET-CT, PET positive mediastinal nodes with standardize uptake value (SUV) >2 even if lymph node size is less than $1 \mathrm{~cm}$, and primary tumor on PET even with SUV $<2$. Peripheral tumor size $<3 \mathrm{~cm}$ without lymph node involvement on CT and PET-CT do not require invasive mediastinal staging $(21,22)$.

ESGE, ERS, and ESTS guidelines recommend a combination of EBUS/EUS over either test alone in mediastinal staging of lung cancer (22). Negative findings on endosonography should be surgically confirmed in patients with suspicious lymph nodes on either CT or PET-CT. ACCP lung cancer guidelines recommend EBUS transbronchial needle aspiration (EBUS-TBNA), EUS fine needle aspiration (EUS-FNA), or the combination of both over surgical staging as the initial test for staging of the mediastinum in NSCLC (21).

\section{Background on EUS}

EUS-FNA is a minimally invasive ultrasound-guided FNA technique that goes through the esophagus. When a linear EBUS ultrasound scope is used to sample tissue through the transesophageal route, the terminology is EUS-B.

The linear convex EUS scope used in EUS is a flexible scope, which is approximately $13 \mathrm{~mm}$ in its outer diameter. It has a wider range of imaging compared with the EBUS scope. It provides $180^{\circ}$ view, which is parallel to the shaft of the endoscope and obtains images at a depth ranging from 3 to $8 \mathrm{~cm}$. EUS can also be performed using a convex EBUS scope (EUS-B). The convex EBUS scope is a flexible scope with a field of vision between $50^{\circ}$ and $80^{\circ}$, which is parallel to the shaft of the endoscope. It can obtain images at a depth between 2 to $5 \mathrm{~cm}$ depending on the scope used. Figure 1 demonstrates the differences in appearance of lymph node stations 7, 4L, and 5 via EBUS and EUS. Although the EUS scope has a better range of imaging, there is no statistically significant difference in the yield when comparing the use of the EUS-B versus EUS scope in sampling mediastinal lymph nodes through the esophagus (23). There is also no difference between EUS-B versus EUS in sampling left adrenal metastases (24). However, conventional EUS scope may be more helpful if the target lesion is in the right adrenal gland, since the right adrenal gland cannot be reached with the EUS-B technique.

\section{Technique}

The technique of needle aspiration with EUS is similar to EBUS. Lymph node puncture is achieved with a quick forward movement advancing the needle. In and out movements are performed with the needle inside the lymph node. It is very important to see the needle moving inside the lymph node and not to move the lymph node with the needle. Balloons filled with saline can be used to overcome poor contact between the ultrasound probe and the esophageal wall. It can assist with obtaining a clear ultrasound image. Although it can help enhance image acquisition, it is unclear if this translates into better diagnostic yield. There are currently no studies comparing balloon use in improving diagnostic yield with endosonography. Of note, for patients with latex allergy, latex-free balloons are available for linear EUS scopes (25).

\section{Lymph node stations and structures accessible by EUS}

EUS-FNA is helpful for accessing lesions close to the esophagus, including lymph nodes in the inferior mediastinum and structures below the diaphragm. The lymph nodes and structures accessible by EUS include 

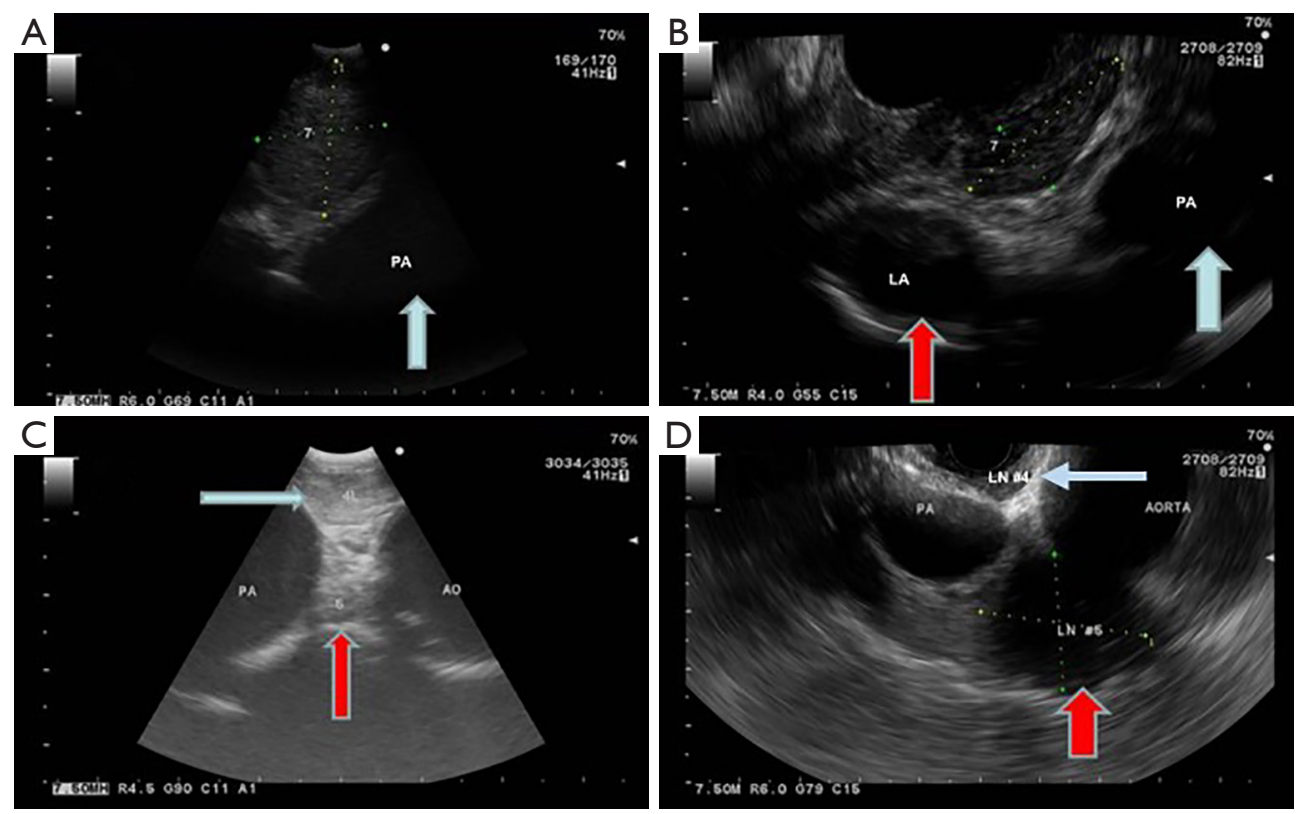

Figure 1 Appearance of lymph nodes and mediastinal structures on endobronchial ultrasound (EBUS) versus endoscopic ultrasound (EUS). (A) Station 7 seen with EBUS. Blue arrow pointing to the pulmonary artery (PA). (B) Station 7 seen with EUS. Red arrow pointing to part of the left atrium (LA), which is seen anterior and distal from the node. Blue arrow pointing to the pulmonary artery. (C) Station 4L (blue arrow) and station 5 (red arrow) seen with EBUS. Aorta (AO) and pulmonary artery are seen cephalad (right side of the screen) and caudal (left side of the screen), respectively, from station $4 \mathrm{~L}$. Station 5 is anterior and lateral (bottom of the screen) from station $4 \mathrm{~L}$ and the pulmonary ligament (not seen). (D) Station 4L (blue arrow) and station 5 (red arrow) seen with EUS. Station 5 is anterior and lateral (bottom of the screen) to the ligamentum arteriosum (not seen).

lymph nodes in stations $2 \mathrm{R}, 2 \mathrm{~L}, 3 \mathrm{P}, 4 \mathrm{~L}, 5,7,8$, 9, celiac axis, left lobe of the liver, bilateral adrenal glands, and spleen (26). Lymph nodes in station $4 \mathrm{R}$ can sometimes be reached if the nodes are large enough $(>2 \mathrm{~cm})$. New techniques to reach the para-aortic station 6 lymph nodes can also be performed using EUS. This can be done with or without traversing the aorta $(27,28)$. Table 1 provides an outline of the lymph node stations and structures accessible with different diagnostic techniques.

\section{Mediastinal lymph nodes}

Although rare, studies have shown that one in 30 patients may have isolated involvement of an inferior mediastinal lymph node without concurrent involvement of upper mediastinal lymph nodes in patients with NSCLC (29). These inferior lymph nodes in stations 8 and 9 cannot be accessed with EBUS. Additionally, access of lymph nodes in the aorto-pulmonary (AP) window and para-aortic area (stations 5 and 6) is not possible with EBUS (30).
EUS can reliably take needle aspirations from the left paratracheal (stations 2L, 4L), subcarinal (station 7), and inferior mediastinal (stations 8,9) lymph nodes. EUS also allows for better visualization of lymph nodes in the AP window and para-aortic area (stations 5, 6). Access to lymph nodes in station $2 \mathrm{R}$ and $4 \mathrm{R}$ is limited due to the intervening trachea, however can sometimes be reached if the lymph nodes are large enough.

AP window lymph nodes and para-aortic lymph nodes are not accessible by standard mediastinoscopy. Typically, Chamberlain procedure (left anterior mediastinotomy), extended cervical mediastinoscopy, or video-assisted thoracoscopic surgery (VATS) is needed to reach these lymph nodes. A new technique to reach the para-aortic (station 6) lymph nodes without traversing the thoracic aorta using EUS-FNA have been described $(27,28)$. In a prior case series of 12 consecutive patients, access of lymph node in station 6 was performed with the needle passing through the proximal esophagus into the mediastinum, directed toward the para-aortic location to reach and enter 
Table 1 Lymph node stations and structures accessible with different diagnostic techniques

\begin{tabular}{|c|c|c|c|}
\hline Lymph nodes/structures & EBUS & EUS & $\mathrm{CM}$ \\
\hline 1: highest mediastinal & $x$ & & $x$ \\
\hline 2R: upper paratracheal right & $x$ & $x$ & $x$ \\
\hline 2L: upper paratracheal left & $\mathrm{x}$ & $x$ & $x$ \\
\hline \multicolumn{4}{|l|}{ 3A: prevascular } \\
\hline 3P: retrotracheal & $x$ & $x$ & \\
\hline 4R: lower paratracheal right & $\mathrm{X}$ & & $x$ \\
\hline $4 \mathrm{~L}$ : lower paratracheal left & $x$ & $x$ & $x$ \\
\hline 5: subaortic (AP window) & & $x$ & \\
\hline 6: para-aortic & & $x$ & \\
\hline 7: subcarinal & $x$ & $x$ & $x$ \\
\hline 8: paraesophageal & & $x$ & \\
\hline 9: pulmonary ligament & & $x$ & \\
\hline 10: hilar & $x$ & & $x$ \\
\hline 11 interlobar & $x$ & & \\
\hline Left lobe of liver & & $x$ & \\
\hline Adrenals & & $x$ & \\
\hline Spleen & & $x$ & \\
\hline
\end{tabular}

" $X$ " indicates that the lymph node station or structure is accessible with the specified diagnostic technique. EBUS, endobronchial ultrasound; EUS, endoscopic ultrasound; CM, cervical mediastinoscopy.

the para-aortic lymph node without piercing the aorta or great vessels. Successful cytologic diagnosis of station 6 lymph nodes were obtained in all cases. No morbidity resulted from the procedure nor was any observed at 30 days after the procedure (29).

\section{Adrenal glands}

Lung cancer with metastases to the adrenals are common (31-33). Isolated adrenal metastasis from lung cancer has been reported (34). EUS-FNA has been demonstrated to safely evaluate adrenal gland involvement (31). To reach the left adrenal gland, the EUS scope is introduced into the stomach and the left kidney is identified by looking backwards to the left. The adrenal is identified with birdlike appearance. To reach the right adrenal gland, the EUS scope is introduced distally deep into the duodenum. Once the right kidney is identified, the scope is slowly withdrawn above and anterior to the right kidney while scanning for the adrenal gland. With the ability to evaluate the adrenal glands with EUS, one can sample both adrenal and lung lesions in the same session, while simultaneously providing accurate disease staging $(33,35)$.

Our previous experience with adrenal sampling using EUS-FNA with $22 \mathrm{G}$ needle included a case series of 13 patients. The presence or absence of metastasis was conclusively established in all 13 patients, providing a diagnostic yield of $100 \%$ (36). This is consistent with previously reported studies $(35,37)$.

\section{Transvascular biopsy}

In a previous retrospective study of 33 consecutive patients who underwent combined EBUS/EUS mediastinal staging, transvascular biopsy was performed via EUS in 19 patients and EBUS in 14 patients. In the study, biopsies via the branches of the pulmonary artery was performed in 14 patients and biopsies via the aorta was performed in 19 patients. Overall yield was $73 \%$. No complication was seen during the immediate post-procedural period. Median follow-up was 12 months, with no complications described (38).

Similarly, Wallace et al. described a transvascular approach in the diagnosis of a 2.6-cm right lower lobe lung mass with $25 \mathrm{G}$ needle via single transaortic pass under linear EUS visualization (39). Additionally, von Bartheld et al. retrospectively reviewed the performance and safety of EUS-guided transaortic approach in 14 patients using a single pass with a $22 \mathrm{G}$ needle and described sensitivity between $64-75 \%$ and specificity of $100 \%$ (40). The lower sensitivity with transvascular approach was thought to be due to the lower number of passes and the targets biopsied $(41,42)$.

\section{Central tumors}

Transesophageal lung biopsy of a central tumor close to the esophagus using EUS can be performed safely (43). A study compared the tolerance, efficacy, and safety of EBUS-TBNA versus transesophageal EUS-guided FNA with EBUS scope for the diagnosis of lesions accessible by both procedures. No difference in accuracy was noted between the two modalities, but it concluded that EUS had the advantage of comparable tolerance with fewer doses of sedatives, shorter procedure time, higher operator 
satisfaction, and fewer oxygen desaturations during the procedure (44).

Our experience with transesophageal lung biopsy of central tumors close to the esophagus using EUS-FNA with a $22 \mathrm{G}$ needle included a case series with 20 patients. Adequate tissue sample was obtained in 19 of 20 patients, all of which led to a definitive diagnosis, with a $95 \%$ diagnostic yield. This is similar to previously reported studies with diagnostic yields between $95-100 \%(43,45-47)$.

\section{Efficacy of EUS}

In one study, the sensitivity, specificity, positive predictive value (PPV), and negative predictive value (NPV) of EUSFNA for cancers of the mediastinum was reported to be $92 \%, 100 \%, 100 \%$, and $80 \%$, respectively (48). Two metaanalysis report pooled sensitivities of EUS-FNA in nodal staging of NSCLC of $83 \%$ and $89 \%(21,49)$. A randomized study of 40 patients by Tournoy et al. compared EUS-FNA versus surgical mediastinoscopy (50). In their study, the sensitivity of EUS-FNA was $93 \%$ compared with $73 \%$ for surgical staging.

The sensitivity of EUS-FNA for detecting occult metastases in a radiographically normal mediastinum is approximately $58 \%$ (49). A prospective study evaluated the role of EUS-FNA in a radiographically normal mediastinum on CT scan. EUS-FNA identified 2 patients with $\mathrm{N} 3$ disease in 56 patients in this group (51). In another trial, EUS-FNA identified N2 disease in 5 out of 47 patients with radiographically normal mediastinum on CT scan (52).

\section{Efficacy of combined EBUS with EUS}

Combining EBUS-TBNA with EUS-FNA/EUS-BFNA provides a much broader ability to biopsy lymph nodes compared with conventional mediastinoscopy in staging NSCLC. It allows for the complete staging of the mediastinum and allows access to commonly involved metastatic structures below the diaphragm.

Wallace et al. demonstrated that combined EUS/EBUS has a sensitivity of $93 \%$ for detecting mediastinal lymph node metastasis (53). In a different study, the sensitivity, specificity, NPV, and diagnostic accuracy of combined EBUS/EUS/ EUS-B were reported as $91 \%, 100 \%, 96 \%$, and $97 \%$, respectively (54). Further review of literature revealed similar consistent sensitivities of combined EBUS/EUS (19,20).

The sensitivity of mediastinal nodal staging in patients with proven or suspected lung cancer is increased when
EUS/EUS-B-FNA is added to EBUS-TBNA (55). In one study, the average increase in sensitivity with combined EBUS-TBNA/EUS-FNA was $21 \%$ compared with EUSFNA alone and $13 \%$ compared with EBUS-TBNA alone (22). In a separate study of 138 patients who underwent combined EBUS/EUS, EUS better identified malignant disease in lymph nodes of stations 5, 6, and 7 (53). Per Korevaar et al., a meta-analysis of 13 studies showed that adding EUS/EUS-B to EBUS increased sensitivity by $12 \%$ and addition of EBUS to EUS/EUS-B increased sensitivity by $22 \%$. The mean sensitivity of a combined approach was $86 \%$ with NPV of $92 \%$ (56).

The increase in sensitivity of diagnosing and staging mediastinal nodes is also true when the EUS portions of the exam is performed using a convex probe EBUS scope (EUS-B). A trial of patients with NSCLC who underwent EBUS and EUS in the same procedure using the bronchoscope rather than an EUS endoscope demonstrated sensitivities of $89 \%$ with EUS-B alone, 92\% with EBUSTBNA alone, and $96 \%$ with combined EBUS-EUS-B (55).

A prospective trial of 166 patients comparing combined EBUS/EUS versus mediastinoscopy showed that combined EBUS/EUS was diagnostic for N2/N3/M1 disease in 14\% of patients whom standard mediastinoscopy findings were negative; preventing futile thoracotomy and invasive VATS procedure (54). This was further validated in a separate multicenter randomized study comparing combined EBUS/ EUS with surgical staging, which also demonstrated that endosonography was more sensitive than surgical staging in N2/N3 lymph node disease (57).

It is important to recognize that EBUS and EUS should not be considered competitive, but rather complementary. Combined EBUS/EUS/EUS-B can potentially replace surgical staging in patients with NSCLC. Consequently, it is important for the provider to choose the best approach depending on the available resources, expertise, and biopsy target location of interest.

\section{Role of combined EBUS/EUS in accessing a radiologically normal mediastinum}

In a prospective trial that looked at combined EBUS and EUS-B for NSCLC staging in radiologically normal mediastinum on CT and PET-CT with clinical N1 disease, the overall sensitivity, accuracy, and NPV were $67 \%, 81 \%$, and $73 \%$, respectively. In this trial, all patients with negative results underwent subsequent mediastinoscopy. By adding mediastinoscopy, the sensitivity and NPV improved to $73 \%$ 
and $91 \%$, respectively (58).

In another study by Szlubowski et al., 120 patients with radiologically normal mediastinum underwent combined EBUS/EUS followed by transcervical extended mediastinal lymphadenectomy (TEMLA) for negative results. In the 99 patients who underwent TEMLA, metastases were diagnosed in 9 patients. NPV of combined EBUS/EUS in this patient population is $91 \%$ (59). The authors concluded that in a radiologically normal mediastinum, surgical exploration of the mediastinum can be omitted if the results of the biopsy done for staging of NSCLC are negative by combined EBUS/EUS $(59,60)$.

\section{Role of combined EBUS/EUS in restaging the mediastinum after chemo-radiotherapy}

Select studies have addressed the issue of restaging the mediastinum by endosonography in order to verify mediastinal lymph node clearance after chemo-radiotherapy for stage IIIA-N2 non-bulky NSCLC in patients being considered for surgery after neoadjuvant chemoradiotherapy $(61,62)$. Needless to say, it is important to identify patients who respond to chemo-radiotherapy since they may benefit from subsequent surgery.

In one study, the sensitivity of EUS-FNA alone for restaging the mediastinum after chemo-radiation is approximately $44 \%$ with a false-negative rate of $58 \%$ (63). Szlubowski et al. evaluated the utility of combined EBUS/ EUS-B in restaging the mediastinum after chemotherapy in 106 patients. In this study, metastasis was diagnosed in 17\% of patients via subsequent TEMLA in patients with negative biopsy specimen via initial combined EBUS/EUS-B. The authors concluded that endosonographic biopsy is generally more difficult and less sensitive compared with initial staging due to post-inflammatory adhesions and fibrosis $(64,65)$.

Currently, ESGE/ERS/ESTS guidelines suggest that restaging after neoadjuvant chemo-radiation may be performed by EBUS-TBNA and/or EUS-B-FNA for detection of persistent nodal disease, but if negative, subsequent invasive surgical mediastinal staging is indicated before radical surgery is attempted (grade C recommendation) (22).

\section{Role of combined EBUS/EUS in diagnosis of granulomas and infections}

Combined EBUS/EUS has excellent yield when assessing granulomas in patients with sarcoidosis. The lymph node architecture is typically not destroyed and the hilum can be visualized. The diagnostic accuracy of combined EBUS/EUS is much higher at $80 \%$ compared with conventional bronchoscopic biopsies at $53 \%$ in patients with sarcoidosis (66).

Role of FNA cytology in diagnosing infection has expanded due to the increase in number of immunocompromised patients and increasing role of endosonographic FNA where infection is a major cause of illness. A previous retrospective study evaluated the utility of EBUS/EUS-FNA in diagnosing pulmonary coccidioidomycosis in 13 patients. In the study, combined EBUS/EUS led to the diagnosis in 9 cases, and 4 cases were diagnosed via EBUS or EUS individually. The study found that the mean time to diagnosis of pulmonary coccidioidomycosis was shorter with EBUS/EUS (1.6 days) compared with BAL (6.3 days), with $\mathrm{P}$ value of 0.003 . No complications were noted in the study. The study concluded that combined endosonography facilitated early and accurate diagnosis of pulmonary coccidioidomycosis (67).

\section{Role of EUS in SBRT}

In patients requiring SBRT, EUS can assist with placement of fiducials within the target lesions in the lung parenchyma close to the esophagus. In a previous case series, fiducial placement using EUS was described in 6 patients using a 19G needle. No significant complications were noted (37).

\section{Benefits of endoscopic techniques}

In experienced hands, mediastinal staging with combined EBUS/EUS can be performed as an outpatient day case under conscious sedation without decreasing the diagnostic yield (68). Compared with traditional mediastinal staging with cervical mediastinoscopy, endoscopic techniques are less invasive and results in lower morbidity, more cost savings, and reduces patient discomfort.

Complications related to endosonographic needle aspiration include mediastinitis, sepsis, abscess, esophageal perforation, pneumothorax, mediastinal hematoma. The complication rate of endosonographic biopsy (EBUS/EUS) techniques is approximately $0.05 \%$ (69). No mortality has been reported in the literature $(70,71)$. This is significantly lower and far less severe compared with the complication rate associated with conventional surgical biopsy. A 
meta-analysis of 5,687 patients by Toloza et al. showed that major morbidity after mediastinoscopy was seen in approximately $2 \%$, including recurrent laryngeal nerve palsy $(0.05 \%)$, hemorrhage $(0.32 \%)$, tracheal injury $(0.09 \%)$, and pneumothorax $(0.09 \%)$ (72). Mortality with surgical mediastinoscopy has been reported to occur in $0.08 \%$, typically related to major vascular injury (73).

While the overall cost of mediastinoscopy is approximately $\$ 12,000$, the cost of EBUS/EUS done as a combined procedure in endoscopy under moderate sedation is approximately $\$ 4,000$ (74). Furthermore, in the Assessment of Surgical sTaging versus Endoscopic Ultrasound in Lung Cancer (ASTER Study) by Rintoul et al., the cost-effectiveness analysis showed that use of combined EBUS/EUS mediastinal staging had lower mean cost and greater mean quality-adjusted life years (75). Since then, multiple other studies have validated the costeffectiveness of endosonographic staging $(76,77)$.

\section{Training and competency}

Expertise and skill of the endoscopist directly impacts the specimen obtained for cytologic interpretation. Systematic training in mediastinal endosonography should be based on knowledge of anatomy, performance on simulators, and supervised performance on patients. Diagnostic yield is highly operator-dependent and learning curve shows substantial variation between individual operators. ATS, ERS, and ACCP recommend 40 procedures for initial competence and 20 procedures per year to maintain competency. Yield and skill of the operator continue to improve after performing approximately 140 procedures (78-82).

\section{Conclusions}

EUS/EUS-B combined with EBUS provides the ability to completely stage the mediastinum and distant metastases that is not attainable with mediastinoscopy, including structures below the diaphragm. The two techniques (EBUS and EUS/EUS-B) should not be considered as competitive, but rather complementary to each other in order to improve mediastinal staging and diagnosis in thoracic malignancy.

We believe that combined EBUS/EUS/EUS-B is the new gold standard in the initial mediastinal staging of NSCLC when performed by an experienced operator. Training in EUS techniques in addition to EBUS allows for diagnosis and complete staging of lung cancer in a single session, thereby decreasing healthcare cost, time delays, increased sedation time, and patient discomfort. With its superior cost-effectiveness and reduced risk profile compared to conventional mediastinoscopy, endoscopic approach has replaced mediastinoscopy as the initial step in lung cancer staging and diagnosis $(2,19,21,22)$.

\section{Acknowledgments}

Funding: None.

\section{Footnote}

Provenance and Peer Review: This article was commissioned by the Guest Editors (Douglas Kyle Hogarth and Jonathan S. Kurman) for the series "Interventional Pulmonology and Advanced Bronchoscopy" published in Shangbai Chest. The article has undergone external peer review.

Conflicts of Interest: Both authors have completed the ICMJE uniform disclosure form (available at http://dx.doi. org/10.21037/shc.2019.11.08). The series "Interventional Pulmonology and Advanced Bronchoscopy" was commissioned by the editorial office without any funding or sponsorship. The authors have no other conflicts of interest to declare.

Ethical Statement: The authors are accountable for all aspects of the work in ensuring that questions related to the accuracy or integrity of any part of the work are appropriately investigated and resolved.

Open Access Statement: This is an Open Access article distributed in accordance with the Creative Commons Attribution-NonCommercial-NoDerivs 4.0 International License (CC BY-NC-ND 4.0), which permits the noncommercial replication and distribution of the article with the strict proviso that no changes or edits are made and the original work is properly cited (including links to both the formal publication through the relevant DOI and the license). See: https://creativecommons.org/licenses/by-nc-nd/4.0/.

\section{References}

1. Parkin DM, Bray F, Ferlay J, et al. Global cancer statistics, 2002. CA Cancer J Clin 2005;55:74-108.

2. Hegde PV, Liberman M. Mediastinal Staging: Endosonographic Ultrasound Lymph Node Biopsy or 
Mediastinoscopy. Thorac Surg Clin 2016;26:243-9.

3. De Wever W, Ceyssens S, Mortelmans L, et al. Additional value of PET-CT in the staging of lung cancer: comparison with CT alone, PET alone and visual correlation of PET and CT. Eur Radiol 2007;17:23-32.

4. Silvestri GA, Gould MK, Margolis ML, et al. Noninvasive staging of non-small cell lung cancer: ACCP evidencedbased clinical practice guidelines (2nd edition). Chest 2007;132:178S-201S.

5. Dales RE, Stark RM, Raman S. Computed tomography to stage lung cancer. Approaching a controversy using metaanalysis. Am Rev Respir Dis 1990;141:1096-101.

6. Lardinois D, Weder W, Hany TF, et al. Staging of nonsmall-cell lung cancer with integrated positron-emission tomography and computed tomography. N Engl J Med 2003;348:2500-7.

7. Cerfolio RJ, Bryant AS, Ojha B, et al. Improving the inaccuracies of clinical staging of patients with NSCLC: a prospective trial. Ann Thorac Surg 2005;80:1207-13; discussion 1213-4.

8. McLoud TC, Bourgouin PM, Greenberg RW, et al. Bronchogenic carcinoma: analysis of staging in the mediastinum with CT by correlative lymph node mapping and sampling. Radiology 1992;182:319-23.

9. Tournoy KG, Maddens S, Gosselin R, et al. Integrated FDG-PET/CT does not make invasive staging of the intrathoracic lymph nodes in non-small cell lung cancer redundant: a prospective study. Thorax 2007;62:696-701.

10. Toloza EM, Harpole L, McCrory DC. Noninvasive staging of non-small cell lung cancer: a review of the current evidence. Chest 2003;123:137S-46S.

11. Silvestri GA, Hoffman B, Reed CE. One from column A: choosing between CT, positron emission tomography, endoscopic ultrasound with fine-needle aspiration, transbronchial needle aspiration, thoracoscopy, mediastinoscopy, and mediastinotomy for staging lung cancer. Chest 2003;123:333-5.

12. Herth FJ, Eberhardt R. Actual role of endobronchial ultrasound (EBUS). Eur Radiol 2007;17:1806-12.

13. Sheski FD, Mathur PN. Endobronchial ultrasound. Chest 2008;133:264-70.

14. Ernst A, Gangadharan SP. A good case for a declining role for mediastinoscopy just got better. Am J Respir Crit Care Med 2008;177:471-2.

15. Rintoul RC, Skwarski KM, Murchison JT, et al. Endoscopic and endobronchial ultrasound real-time fineneedle aspiration for staging of the mediastinum in lung cancer. Chest 2004;126:2020-2.
16. Penman I, Fergusson RJ. Endoscopic ultrasound: a useful tool to assess the mediastinum in patients with lung cancer? Thorax 2002;57:95-6.

17. LeBlanc JK, Espada R, Ergun G. Non-small cell lung cancer staging techniques and endoscopic ultrasound: tissue is still the issue. Chest 2003;123:1718-25.

18. Ernst A, Eberhardt R, Krasnik M, et al. Efficacy of endobronchial ultrasound-guided transbronchial needle aspiration of hilar lymph nodes for diagnosing and staging cancer. J Thorac Oncol 2009;4:947-50.

19. Annema JT, van Meerbeeck JP, Rintoul RC, et al. Mediastinoscopy vs endosonography for mediastinal nodal staging of lung cancer: a randomized trial. JAMA 2010;304:2245-52.

20. Yasufuku K, Pierre A, Darling G, et al. A prospective controlled trial of endobronchial ultrasound-guided transbronchial needle aspiration compared with mediastinoscopy for mediastinal lymph node staging of lung cancer. J Thorac Cardiovasc Surg 2011;142:1393400.e1.

21. Silvestri GA, Gonzalez AV, Jantz MA, et al. Methods for staging non-small cell lung cancer: Diagnosis and management of lung cancer, 3rd ed: American College of Chest Physicians evidence-based clinical practice guidelines. Chest 2013;143:e211S-50S.

22. Vilmann P, Clementsen PF, Colella S, et al. Combined endobronchial and esophageal endosonography for the diagnosis and staging of lung cancer: European Society of Gastrointestinal Endoscopy (ESGE) Guideline, in cooperation with the European Respiratory Society (ERS) and the European Society of Thoracic Surgeons (ESTS). Endoscopy 2015;47:545-59.

23. Szlubowski A, Soja J, Kocon P, et al. A comparison of the combined ultrasound of the mediastinum by use of a single ultrasound bronchoscope versus ultrasound bronchoscope plus ultrasound gastroscope in lung cancer staging: a prospective trial. Interact Cardiovasc Thorac Surg 2012;15:442-6.

24. Crombag LMMJ, Szlubowski A, Stigt JA, et al. EUSB-FNA vs conventional EUS-FNA for left adrenal gland analysis in lung cancer patients. Lung Cancer 2017;108:38-44.

25. Baker JJ, Solanki PH, Schenk DA, et al. Transbronchial fine needle aspiration of the mediastinum. Importance of lymphocytes as an indicator of specimen adequacy. Acta Cytol 1990;34:517-23.

26. Colella S, Vilmann P, Konge L, et al. Endoscopic ultrasound in the diagnosis and staging of lung cancer. 
Endosc Ultrasound 2014;3:205-12.

27. Liberman M, Duranceau A, Grunenwald E, et al. Initial experience with a new technique of endoscopic and ultrasonographic access for biopsy of para-aortic (station 6) mediastinal lymph nodes without traversing the aorta. J Thorac Cardiovasc Surg 2012;144:787-92; discussion 792-3.

28. Liberman M, Duranceau A, Grunenwald E, et al. New technique performed by using EUS access for biopsy of para-aortic (station 6) mediastinal lymph nodes without traversing the aorta (with video). Gastrointest Endosc 2011;73:1048-51.

29. Hegde P, Liberman M. Echo-endoscopic lymph node staging in lung cancer: an endoscopic alternative. Expert Rev Anticancer Ther 2015;15:1063-73.

30. Obiols C, Call S, Rami-Porta R, et al. Survival of patients with unsuspected pN2 non-small cell lung cancer after an accurate preoperative mediastinal staging. Ann Thorac Surg 2014;97:957-64.

31. Patil R, Ona MA, Papafragkakis C, et al. Endoscopic ultrasound-guided fine-needle aspiration in the diagnosis of adrenal lesions. Ann Gastroenterol 2016;29:307-11.

32. Lee MJ, Hahn PF, Papanicolaou N, et al. Benign and malignant adrenal masses: CT distinction with attenuation coefficients, size, and observer analysis. Radiology 1991;179:415-8.

33. Pennathur A, Luketich JD, Heron DE, et al. Stereotactic radiosurgery for the treatment of stage I non-small cell lung cancer in high-risk patients. J Thorac Cardiovasc Surg 2009;137:597-604.

34. Sarela AI, Murphy I, Coit DG, et al. Metastasis to the adrenal gland: the emerging role of laparoscopic surgery. Ann Surg Oncol 2003;10:1191-6.

35. Schuurbiers OC, Tournoy KG, Schoppers HJ, et al. EUSFNA for the detection of left adrenal metastasis in patients with lung cancer. Lung Cancer 2011;73:310-5.

36. Pais FM, Shah RA, Vempilly JJ, et al. Transesophageal approach to lung, adrenal biopsy and fiducial placement using endoscopic ultrasonography (EUS): An interventional pulmonology experience. Initial experience of the UCSF-FRETOC (fresno tracheobronchial \& oesophageal center) study group. Respir Med 2018;141:52-5.

37. Puri R, Thandassery RB, Choudhary NS, et al. Endoscopic ultrasound-guided fine-needle aspiration of the adrenal glands: analysis of 21 patients. Clin Endosc 2015;48:16570.

38. Kazakov J, Hegde P, Tahiri M, et al. Endobronchial and
Endoscopic Ultrasound-Guided Transvascular Biopsy of Mediastinal, Hilar, and Lung Lesions. Ann Thorac Surg 2017;103:951-5.

39. Wallace MB, Woodward TA, Raimondo M, et al. Transaortic fine-needle aspiration of centrally located lung cancer under endoscopic ultrasound guidance: the final frontier. Ann Thorac Surg 2007;84:1019-21.

40. von Bartheld MB, Rabe KF, Annema JT. Transaortic EUS-guided FNA in the diagnosis of lung tumors and lymph nodes. Gastrointest Endosc 2009;69:345-9.

41. Lee HS, Lee GK, Lee HS, et al. Real-time endobronchial ultrasound-guided transbronchial needle aspiration in mediastinal staging of non-small cell lung cancer: how many aspirations per target lymph node station? Chest 2008;134:368-74.

42. LeBlanc JK, Ciaccia D, Al-Assi MT, et al. Optimal number of EUS-guided fine needle passes needed to obtain a correct diagnosis. Gastrointest Endosc 2004;59:475-81.

43. Nasir BS, Edwards M, Tiffault V, et al. Transesophageal pulmonary nodule biopsy using endoscopic ultrasonography. J Thorac Cardiovasc Surg 2014;148:850-5.

44. Oki M, Saka H, Ando M, et al. Transbronchial vs transesophageal needle aspiration using an ultrasound bronchoscope for the diagnosis of mediastinal lesions: a randomized study. Chest 2015;147:1259-66.

45. Annema JT, Veseliç M, Rabe KF. EUS-guided FNA of centrally located lung tumours following a non-diagnostic bronchoscopy. Lung Cancer 2005;48:357-61.

46. Varadarajulu S, Hoffman BJ, Hawes RH, et al. EUSguided FNA of lung masses adjacent to or abutting the esophagus after unrevealing CT-guided biopsy or bronchoscopy. Gastrointest Endosc 2004;60:293-7.

47. Bugalho A, Ferreira D, Eberhardt R, et al. Diagnostic value of endobronchial and endoscopic ultrasoundguided fine needle aspiration for accessible lung cancer lesions after non-diagnostic conventional techniques: a prospective study. BMC Cancer 2013;13:130.

48. Larsen SS, Krasnik M, Vilmann P, et al. Endoscopic ultrasound guided biopsy of mediastinal lesions has a major impact on patient management. Thorax 2002;57:98-103.

49. Micames CG, McCrory DC, Pavey DA, et al. Endoscopic ultrasound-guided fine-needle aspiration for non-small cell lung cancer staging: A systematic review and metaanalysis. Chest 2007;131:539-48.

50. Tournoy KG, De Ryck F, Vanwalleghem LR, et al. Endoscopic ultrasound reduces surgical mediastinal staging in lung cancer: a randomized trial. Am J Respir Crit Care 
Med 2008;177:531-5.

51. Yasuda I, Kato T, Asano F, et al. Mediastinal lymph node staging in potentially resectable non-small cell lung cancer: a prospective comparison of CT and EUS/EUS-FNA. Respiration 2009;78:423-31.

52. Fernández-Esparrach G, Ginès A, Belda J, et al. Transesophageal ultrasound-guided fine needle aspiration improves mediastinal staging in patients with non-small cell lung cancer and normal mediastinum on computed tomography. Lung Cancer 2006;54:35-40.

53. Wallace MB, Pascual JM, Raimondo M, et al. Minimally invasive endoscopic staging of suspected lung cancer. JAMA 2008;299:540-6.

54. Liberman M, Sampalis J, Duranceau A, et al. Endosonographic mediastinal lymph node staging of lung cancer. Chest 2014;146:389-97.

55. Herth FJ, Krasnik M, Kahn N, et al. Combined endoscopic-endobronchial ultrasound-guided fine-needle aspiration of mediastinal lymph nodes through a single bronchoscope in 150 patients with suspected lung cancer. Chest 2010;138:790-4.

56. Korevaar DA, Crombag LM, Cohen JF, et al. Added value of combined endobronchial and oesophageal endosonography for mediastinal nodal staging in lung cancer: a systematic review and meta-analysis. Lancet Respir Med 2016;4:960-8.

57. Yasufuku K, Nakajima T, Motoori K, et al. Comparison of endobronchial ultrasound, positron emission tomography, and CT for lymph node staging of lung cancer. Chest 2006;130:710-8.

58. Dooms C, Tournoy KG, Schuurbiers O, et al. Endosonography for mediastinal nodal staging of clinical N1 non-small cell lung cancer: a prospective multicenter study. Chest 2015;147:209-15.

59. Szlubowski A, Zieliński M, Soja J, et al. A combined approach of endobronchial and endoscopic ultrasoundguided needle aspiration in the radiologically normal mediastinum in non-small-cell lung cancer staging--a prospective trial. Eur J Cardiothorac Surg 2010;37:1175-9.

60. Hegde P, Molina JC, Thivierge-Southidara M, et al. Combined Endosonographic Mediastinal Lymph Node Staging in Positron Emission Tomography and Computed Tomography Node-Negative Non-Small-Cell Lung Cancer in High-Risk Patients. Semin Thorac Cardiovasc Surg 2019. [Epub ahead of print].

61. Genestreti G, Burgio MA, Matteucci F, et al. Endobronchial/Endoesophageal Ultrasound (EBUS/EUS) Guided Fine Needle Aspiration (FNA) and 18F-FDG
PET/CT Scanning in Restaging of Locally Advanced Non-small Cell Lung Cancer (NSCLC) Treated with Chemo-radiotherapy: A Mono-institutional Pilot Experience. Technol Cancer Res Treat 2015;14:721-7.

62. Szlubowski A, Herth FJ, Soja J, et al. Endobronchial ultrasound-guided needle aspiration in non-small-cell lung cancer restaging verified by the transcervical bilateral extended mediastinal lymphadenectomy- a prospective study. Eur J Cardiothorac Surg 2010;37:1180-4.

63. von Bartheld MB, Versteegh MI, Braun J, et al. Transesophageal ultrasound-guided fine-needle aspiration for the mediastinal restaging of non-small cell lung cancer. J Thorac Oncol 2011;6:1510-5.

64. Szlubowski A, Zieliński M, Soja J, et al. Accurate and safe mediastinal restaging by combined endobronchial and endoscopic ultrasound-guided needle aspiration performed by single ultrasound bronchoscope. Eur J Cardiothorac Surg 2014;46:262-6.

65. Muthu V, Sehgal IS, Dhooria S, et al. Efficacy of Endosonographic Procedures in Mediastinal Restaging of Lung Cancer After Neoadjuvant Therapy: A Systematic Review and Diagnostic Accuracy Meta-Analysis. Chest 2018;154:99-109.

66. von Bartheld MB, Dekkers OM, Szlubowski A, et al. Endosonography vs conventional bronchoscopy for the diagnosis of sarcoidosis: the GRANULOMA randomized clinical trial. JAMA 2013;309:2457-64.

67. Shah RA, Vempilly JJ, Noor U1 Husnain SM, et al. Combined Endosonography Reduces Time to Diagnose Pulmonary Coccidioidomycosis. J Bronchology Interv Pulmonol 2018;25:152-5.

68. Casal RF, Lazarus DR, Kuhl K, et al. Randomized trial of endobronchial ultrasound-guided transbronchial needle aspiration under general anesthesia versus moderate sedation. Am J Respir Crit Care Med 2015;191:796-803.

69. von Bartheld M, van der Heijden E, Annema J. Mediastinal abscess formation after EUS-guided FNA: are patients with sarcoidosis at increased risk? Gastrointest Endosc 2012;75:1104-7.

70. von Bartheld MB, van Breda A, Annema JT. Complication rate of endosonography (endobronchial and endoscopic ultrasound): a systematic review. Respiration 2014;87:343-51.

71. Liberman M, Duranceau A, Martin J, et al. Major airway laceration secondary to endobronchial ultrasound transbronchial lymph node biopsy. J Bronchology Interv Pulmonol 2010;17:264-5.

72. Toloza EM, Harpole L, Detterbeck F, et al. Invasive 
staging of non-small cell lung cancer: a review of the current evidence. Chest 2003;123:157S-66S.

73. Lemaire A, Nikolic I, Petersen T, et al. Nine-year single center experience with cervical mediastinoscopy: complications and false negative rate. Ann Thorac Surg 2006;82:1185-9.

74. Eloubeidi MA, Tamhane A, Chen VK, et al. Endoscopic ultrasound-guided fine-needle aspiration in patients with non-small cell lung cancer and prior negative mediastinoscopy. Ann Thorac Surg 2005;80:1231-9.

75. Rintoul RC, Glover MJ, Jackson C, et al. Cost effectiveness of endosonography versus surgical staging in potentially resectable lung cancer: a health economics analysis of the ASTER trial from a European perspective. Thorax 2014;69:679-81.

76. Søgaard R, Fischer BM, Mortensen J, et al. The optimality of different strategies for supplemental staging of nonsmall-cell lung cancer: a health economic decision analysis. Value Health 2013;16:57-65.

77. Ang SY, Tan RW, Koh MS, et al. Economic analysis

\section{doi: 10.21037/shc.2019.11.08}

Cite this article as: Ho E, Hegde P. Endoscopic ultrasound in interventional pulmonology. Shanghai Chest 2020;4:17. of endobronchial ultrasound (EBUS) as a tool in the diagnosis and staging of lung cancer in Singapore. Int J Technol Assess Health Care 2010;26:170-4.

78. Medford ARL. Learning curve for endobronchial ultrasound-guided transbronchial needle aspiration. Chest 2012;141:1643.

79. Fernández-Villar A, Leiro-Fernández V, Botana-Rial M, et al. The endobronchial ultrasound-guided transbronchial needle biopsy learning curve for mediastinal and hilar lymph node diagnosis. Chest 2012;141:278-9.

80. Ernst A, Silvestri GA, Johnstone D. Interventional pulmonary procedures: Guidelines from the American College of Chest Physicians. Chest 2003;123:1693-717.

81. Bolliger CT, Mathur PN, Beamis JF, et al. ERS/ATS statement on interventional pulmonology. European Respiratory Society/American Thoracic Society. Eur Respir J 2002;19:356-73.

82. Block MI. Endobronchial ultrasound for lung cancer staging: how many stations should be sampled? Ann Thorac Surg 2010;89:1582-7. 